\title{
An improved method for the isolation and culture of rat pancreatic ductal epithelial cells
}

\author{
Renjie Chang ${ }^{1 \#}$, Heping Qin ${ }^{2 \#}$, Zhihai Liang ${ }^{1}$, Mengbin Qin ${ }^{3}$, Huilin Wang ${ }^{4}$, Yule Wei ${ }^{1}$, Hongzong Fu ${ }^{5}$, \\ Huali Huang ${ }^{6}$, Guodu Tang ${ }^{1}$
}

${ }^{1}$ Department of Gastroenterology, The First Affiliated Hospital of Guangxi Medical University, Nanning 530021, China; ${ }^{2}$ Department of Gastroenterology, Liuzhou People's Hospital, Liuzhou 545006, China; ${ }^{3}$ Department of Gastroenterology, Second Affiliated Hospital of Guangxi Medical University, Nanning 530007, China; ${ }^{4}$ Department of Chemotherapy, Affiliated Tumor Hospital of Guangxi Medical University, Nanning 530021, China; ${ }^{5}$ Guangxi International Zhuang Medical Hospital, Nanning 530001, China; ${ }^{6}$ Department of Gastroenterology of The First People's Hospital of Nanning City, Nanning 530022, China

Contributions: (I) Conception and design: G Tang, Z Liang, M Qin; (II) Administrative support: G Tang; (III) Provision of study materials or patients: H Wang, Y Wei, H Fu, H Huang; (IV) Collection and assembly of data: R Chang, H Qin; (V) Data analysis and interpretation: H Qin, R Chang; (VI) Manuscript writing: All authors; (VII) Final approval of manuscript: All authors.

"These authors contributed equally to this work.

Correspondence to: Professor Guodu Tang. Department of Gastroenterology, The First Affiliated Hospital of Guangxi Medical University, Nanning 530021, China. Email: tguodu02@126.com.

Background: This aim of this study was to explore a novel method that can be used to isolate and culture rat pancreatic ductal epithelial cells.

Methods: Retrograde injection of indigo carmine solution into the bile duct of rats revealed the main pancreatic duct, which was isolated using the naked eye (without using a stereomicroscope). The main pancreatic duct was sequentially digested with three enzymes, and the digested cells were cultured in RPMI1640 medium containing 10-15\% fetal bovine serum. After $72 \mathrm{~h}$, the primary pancreatic ductal epithelial cells started to adhere to the wall. The cells reached $70-80 \%$ confluence after approximately 7 days and were subsequently digested with $0.25 \%$ trypsin and subcultured. Cells of the second and fourth passages were harvested. Cytokeratin (CK)-7 and CK-19 protein expressions in the cells and pancreatic tissue were detected by Western blot analysis. q-PCR was employed to examine CK-7, CK-19, somatostatin, amylase, insulin, and glucagon mRNA expression in the cells and pancreatic tissue after the main pancreatic duct was removed.

Results: The rats had one or two main pancreatic ducts meeting the bile ducts at a right or an acute angle. Rat pancreatic ductal epithelial cells isolated by this method grew well and showed a cobblestonelike appearance via microscopy. Western blot analysis showed that both the second and fourth passages of pancreatic ductal epithelial cells expressed CK-7 and CK-19 protein. The q-PCR results showed the expression of CK-7 and CK-19 genes in the second and fourth passages of pancreatic ductal epithelial cells, while the somatostatin, amylase, insulin, and glucagon genes were not expressed. The pancreatic tissue harvested after the removal of the main pancreatic duct did not express CK-7 or CK-19, while the somatostatin, amylase, insulin, and glucagon genes were expressed.

Conclusions: The preliminary results show that this method can be applied to successfully isolate and culture rat pancreatic ductal epithelial cells.

Keywords: Pancreatic ductal epithelial cells; cell culture; rat; in vitro

Submitted Feb 05, 2020. Accepted for publication Feb 24, 2020.

doi: $10.21037 /$ atm.2020.03.75

View this article at: http://dx.doi.org/10.21037/atm.2020.03.75 


\section{Introduction}

Pancreatic ductal epithelial cells make up the structural basis of pancreatic ducts and have a close association with the pathogenesis of pancreatitis, pancreatic cystic fibrosis, and pancreatic ductal cell adenocarcinoma $(1,2)$. With stem cell potential, they can be cultured in vitro, amplified, and induced to differentiate into pancreatic endocrine cells. Therefore, they could hold the key to resolving the issue of a donor shortage for clinical islet cell transplantation $(3,4)$.

Owing to the complex nature of the pancreas, with its endocrine and exocrine functions and its composition of several different cell types, the in vitro culture of pancreatic ductal epithelial cells is not easy (5). Moreover, pancreatic ductal epithelial cells account for only a small proportion of total pancreatic cells; for example, they account for only $3-4 \%$ and $5-10 \%$ of pancreatic cells in rodents and humans, respectively $(1,6)$.

Several culture methods have been reported for pancreatic ductal epithelial cells from humans (7-9) and other species, including hamsters $(6,10)$, guinea pigs(11), rhesus monkeys (12), bovines (13), mice $(14,15)$, and rats (16-18).

The main pancreatic ductal epithelial cell culture methods can be summarized as follows: (I) the main pancreatic duct is removed using the naked eye and then digested with collagenase. This method is mainly used in humans, bovines and pigs; (II) the entire pancreas is removed and digested with collagenase. This method is mainly used in rhesus monkeys, hamsters, mice, and rats; and (III) the head region of the pancreas is removed, and the main pancreatic duct is isolated under a stereo microscope and digested with enzymes. This method is mainly used in mice and rats.

These traditional methods are complicated and time consuming. Therefore, in this study, we attempted improve the methods detailed by previous reports (19). First, retrograde injection of indigo carmine solution was used to determine the location of the main pancreatic duct in the rats. Next, with the naked eye, the removal of the main pancreatic duct was carried out. Finally, the pancreatic ductal epithelial cells were isolated and subcultured using a digestive culture method. The method is reported in detail herein.

\section{Methods}

\section{Main experimental materials}

* Male Sprague-Dawley (SD) rats (250-350 g, Experimental
Animal Center of Guangxi Medical University, Nanning, China);

* $0.2 \%$ indigo carmine mucosa staining solution (Nanjing Minimally Invasive Medicine Technology Co., Ltd. Nanjing, China);

* Collagenase V (Sigma, St. Louis, MO, USA);

* Neutral protease (Sangon Biotech (Shanghai) Co., Ltd., Shanghai, China);

* Trypsin (containing EDTA) (Beijing Solarbio Science \& Technology Co., Ltd., Beijing, China);

* Fetal bovine serum (LONSERA, Shanghai Shuangru Biology Science\&Technology Co.,Ltd, Shanghai, China);

* CK7 (Aibokang (Shanghai) Trade Co., Ltd. Shanghai, China);

* RPMI-1640 (Corning, New York,USA);

* Anti-CK19 (SANTA CRUZ, Texas, USA);

* T12.5 disposable cell culture flasks (Guangzhou Jet Biofiltration Co., Ltd., Guangzhou, China);

* Complete medium: $10-15 \%$ fetal bovine serum + RPMI 1640.

\section{Experimental methods}

Retrograde injection of indigo carmine solution via the duodenal papilla

Three rats were selected for each experiment. The rats were subjected to fasting for $24 \mathrm{~h}$, before they were anaesthetized with an intraperitoneal injection of $10 \%$ chloral hydrate solution $(3 \mathrm{~mL} / \mathrm{kg})$. The chest and abdomen were disinfected with iodophor, and an incision was made in the upper abdomen midline. Surgical scissors were used to make an incision in the abdominal wall. The pancreas was then identified along the stomach, and the duodenum was exposed. The common bile duct was clamped with a $3.5 \mathrm{~cm}$ blood vessel clamp near the hilum of the liver. The duodenal papilla was identified along the inner side of the duodenum. A $1 \mathrm{~mL}$ syringe was used to perforate the duodenal wall on the opposite side of the duodenal papilla and was inserted approximately $0.5 \mathrm{~cm}$ into the common bile duct for retrograde injection of $0.2 \%$ indigo carmine mucosa staining solution.

\section{Removal of the main pancreatic duct}

The main pancreatic duct was separated from the surrounding tissue along its direction using microscissors and microforceps. After successful separation, it was cut with microscissors and placed in phosphate-buffered saline (PBS). 
Culture of rat primary pancreatic ductal epithelial cells using a digestive culture method

(I) The separated main pancreatic duct was placed in $2 \mathrm{mg} / \mathrm{mL}$ collagenase $\mathrm{V}$ solution, digested in a $37{ }^{\circ} \mathrm{C}$ water bath for $5 \mathrm{~min}$, and shaken once at 1,3 , and $5 \mathrm{~min}$

(II) Digestion was halted by the addition of $10 \mathrm{~mL}$ of PBS, and the PBS and floating substances were then discarded. This step was repeated once.

(III) Four milliliters of sterile PBS and $1 \mathrm{~mL}$ of $2 \mathrm{U} / \mathrm{mL}$ neutral protease solution were added, and the sample was incubated in a $37^{\circ} \mathrm{C}$ water bath for approximately 8-12 min, with vibration once every $4 \mathrm{~min}$.

(IV) Digestion was halted by the addition of $5-8 \mathrm{~mL}$ of PBS, and the PBS and floating substances were then discarded. This step was repeated once.

(V) The tissue was digested in $37^{\circ} \mathrm{C}$ pre-warmed trypsin for $3 \mathrm{~min}$; this procedure was conducted a total of 5 times. Then, the tissue was digested with $2 \mathrm{~mL}$ of $0.1 \%$ trypsin at $37{ }^{\circ} \mathrm{C}$ for $3-5 \mathrm{~min}$, and $1 \mathrm{~mL}$ of fetal bovine serum (FBS) was added to terminate digestion. The first supernatant was discarded, and the second through to the fifth supernatants were collected into a $15 \mathrm{~mL}$ sterile centrifuge tube.

(VI) The sample was centrifuged at 1,000 rpm for $5 \mathrm{~min}$. Then, the cell pellet was resuspended in complete medium, and the cells were transferred to a T12.5 flask and cultured in a $5 \% \mathrm{CO}_{2}$ incubator at $37{ }^{\circ} \mathrm{C}$ for 48-72 h without a change of medium.

\section{Subculture of pancreatic ductal epithelial cells}

(I) After 48-72 h of culture, the growth of primary rat pancreatic ductal epithelial cells was observed under a microscope. The cells were washed with PBS to remove unattached cells, and fresh complete medium was added.

(II) After a further 4-5 days of culture, adherent cells that reached $70-80 \%$ confluence were digested with $0.25 \%$ trypsin and subcultured. The second and fourth passages of pancreatic ductal epithelial cells were harvested for characterization.

Identification of rat pancreatic ductal epithelial cells Western blot to identify pancreatic ductal epithelial cells

The second and fourth passages of pancreatic ductal epithelial cells were collected, and the cell lysates were investigated for CK-7 and CK-19 protein expression using the following procedure: The cells were collected using a cell scrapper, lysed with radioimmunoprecipitation assay (RIPA) buffer on ice for $30 \mathrm{~min}$, and centrifuged at 12,000 rpm for $15 \mathrm{~min}$. The supernatant was collected, and the protein concentration was measured. An appropriate volume of loading buffer was added to ensure equal protein loads, and the samples were boiled for 3-5 min. Twenty microliters of protein sample was separated using SDS-PAGE on a $12 \%$ separation gel and $5 \%$ stacking gel. The protein was transferred to a polyvinylidene fluoride (PVDF) membrane., which was then washed with deionized water, blocked in $5 \% \mathrm{BSA}$ at room temperature for $1 \mathrm{~h}$, and incubated with primary antibody overnight at $4{ }^{\circ} \mathrm{C}$. Following this, the membrane was washed with $1 \times$ TBS-T buffer 3 times, transferred into the corresponding horseradish peroxidase (HRP)-conjugated secondary antibody solution, and incubated for $4-5 \mathrm{~h}$ at room temperature. The membrane was developed in enhanced chemiluminescent (ECL) solution.

q-PCR analysis of pancreatic ductal epithelial cells

Total RNA from the second and fourth passages of cultured pancreatic ductal epithelial cells and pancreatic tissue harvested after removal of the main pancreatic duct were extracted using TRIzol and were reverse-transcribed into cDNA in line with the manufacturer's instructions. The PCR conditions were as follows: $95^{\circ} \mathrm{C}$ for $2 \mathrm{~min}$, and 40 cycles of $95^{\circ} \mathrm{C}$ for $2 \mathrm{~s}$, and $60^{\circ} \mathrm{C}$ for $30 \mathrm{~s}$. The primers are listed in Table 1.

\section{Results}

\section{Indigo carmine staining of the main pancreatic duct}

The main pancreatic duct was revealed after retrograde injection of $0.2 \%$ indigo carmine mucosa staining solution via the duodenal papilla. This study showed that one or two main pancreatic ducts in the rats intersected with the bile duct at a right angle or an acute angle (Figure 1).

\section{Observation of primary rat pancreatic ductal epithelial cells}

After 72 hours of culture, the cells were viewed under an inverted phase contrast microscope. The cells were observed to have crawled from the center of the main pancreatic duct tissue growing densely and adherently grown with a cobblestone appearance (Figure 2A,B). The peripheral cells grew sparsely (Figure 2C,D). 
Table 1 Primers for q-PCR

\begin{tabular}{lll}
\hline Gene & 5'-primer & 3'-primer \\
\hline GAPDH & ACAGCAACAGGGTGGTGGAC & TTTGAGGGTGCAGCGAACTT \\
CK-7 & GAACCAGCGTGCCAAGTTAGAG & AGATAAGCTTGCCACCATTGCC \\
CK-19 & CGCATCGTGTCCTCATCCTC & TGTTCTGTCTCAAACTTGGTCCG \\
Glucagon & ACCGTTACATCGTGGCTGG & GGGAAGCTGGGAATGATCTGG \\
Amylase & TCGCAAATGGAATGGAGAGAAGAT & GGCAACCATGTTCCTGATTTGAC \\
Insulin & GATGCCACCAATCCTTCCGT & GGCCGAGTCGTCATACTCAC \\
Somatostatin & GAGATGCTGTCCTGCCGTCT & TACTTGGCCAGTTCCTGTTTCCCG \\
\hline
\end{tabular}
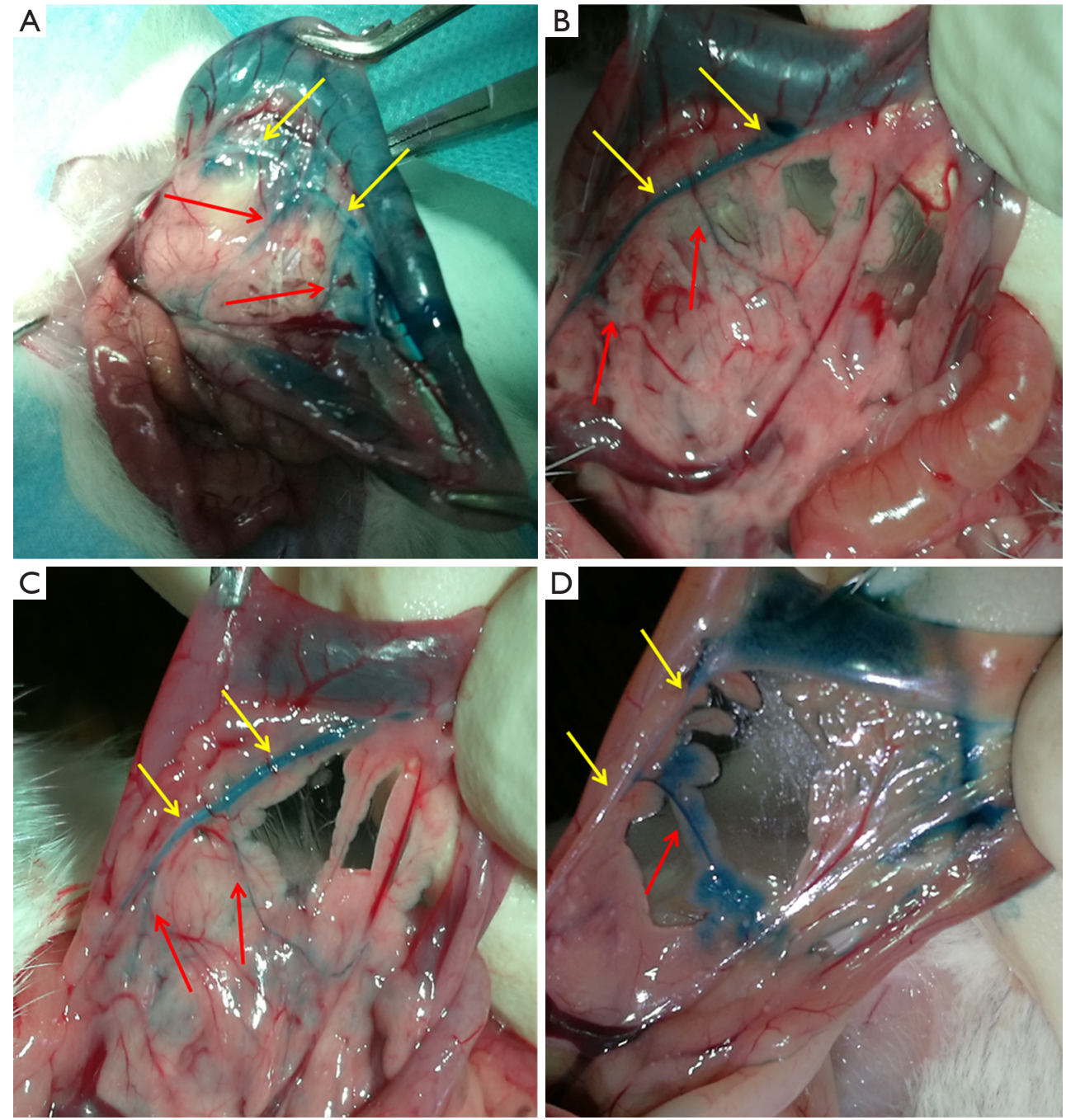

Figure 1 The bile ducts (yellow arrows) and main pancreatic ducts (red arrows) removed from the rats. 

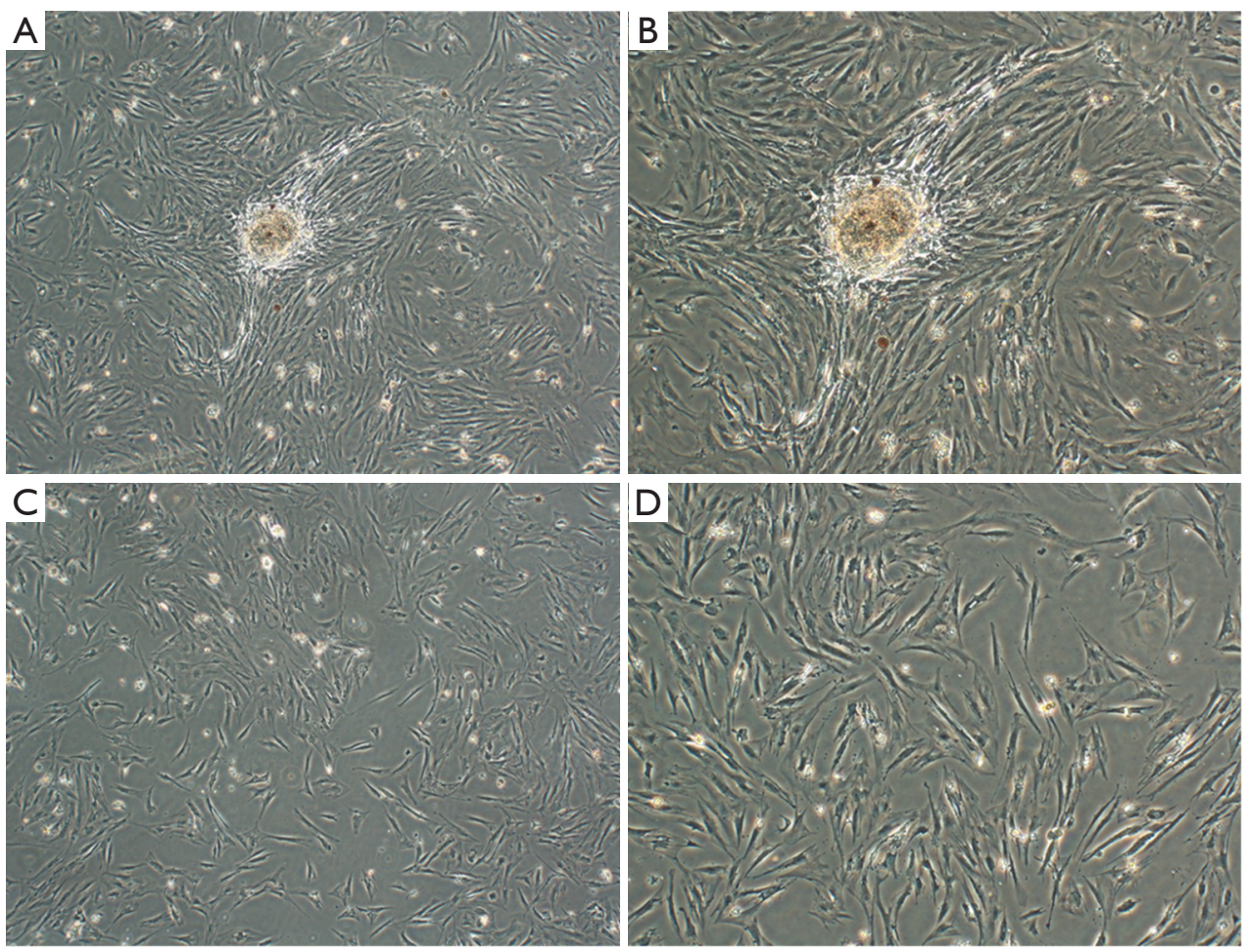

Figure 2 Observation of primary rat pancreatic ductal epithelial cells after $72 \mathrm{~h}$ of culture. (A,C) Images of the rat pancreatic ductal cells epithelial cells after $72 \mathrm{~h}$ of culture (40x); and (B,D) after $72 \mathrm{~h}$ of culture (100x).

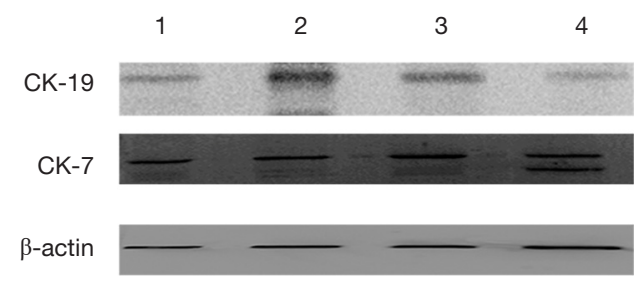

Figure 3 Western blot to identify the second and fourth passages of pancreatic ductal epithelial cells. $(1,2)$ Second passage; $(3,4)$ fourth passage.

\section{Western blot results}

CK-7 and CK-19 were expressed in the second and fourth passage cells after subculture (Figure 3).

\section{q-PCR results}

After subculture, the second and fourth generation cells expressed CK-7 and CK-19, but not somatostatin, amylase, insulin and glucagon genes. However, the pancreatic tissues without the main pancreatic duct expressed somatostatin, amylase, insulin, and glucagon genes, but not CK-7 and CK-19 (Figure 4).

\section{Discussion}

In this study, retrograde injection of $0.2 \%$ indigo carmine mucosa staining solution was used to determine the location of the main pancreatic duct in rats. This study found that there were variations in the main pancreatic duct of rats and that there were one or two main pancreatic ducts that intersected with the common bile duct at a right angle or an acute angle. After determining the direction of the main pancreatic duct, the main pancreatic duct was accurately removed with the naked eye, without using a stereo microscope. Primary pancreatic ductal epithelial cells from the rats were acquired after collagenase, neutral protease, and trypsin digestion.

The culture medium is the basic growth solution and is an important factor for maintaining the growth of cells in vitro. In previous reports, RPMI-1640 or a 1:1 mixture of Hams F12 and DMEM was used as the base medium, and complete medium was prepared with the addition of different concentrations of penicillin-streptomycin, 
A

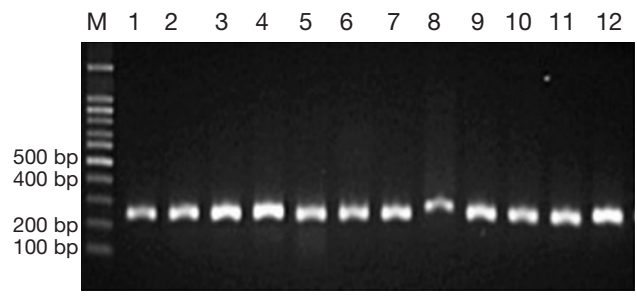

C

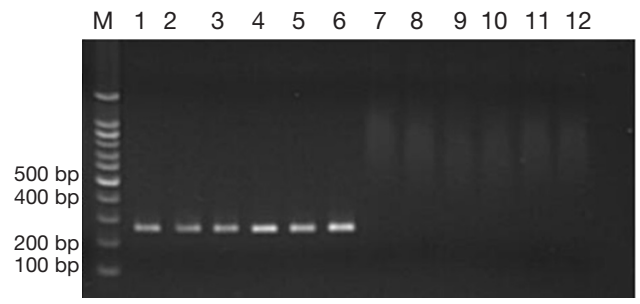

E

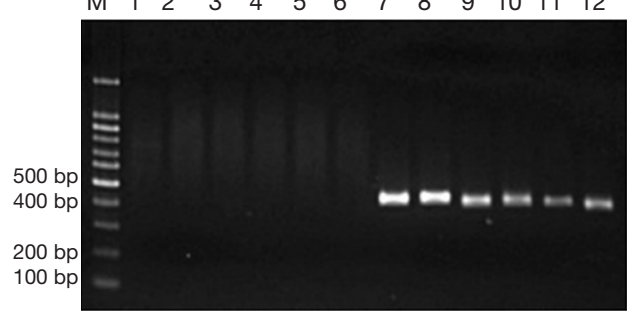

G

$\begin{array}{lllllllllllll}M & 1 & 2 & 3 & 4 & 5 & 6 & 7 & 8 & 9 & 10 & 11 & 12\end{array}$
B

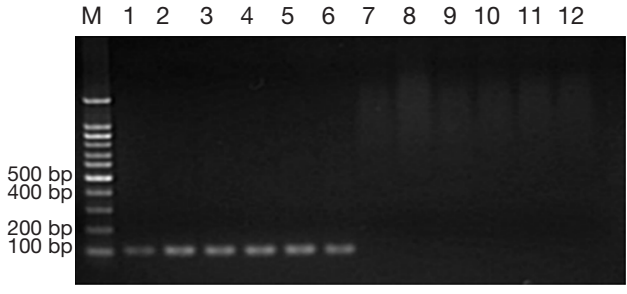

D

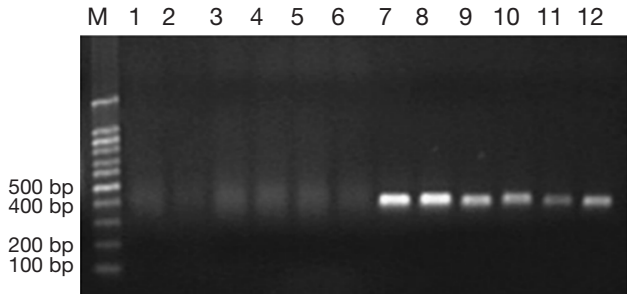

$\mathrm{F}$

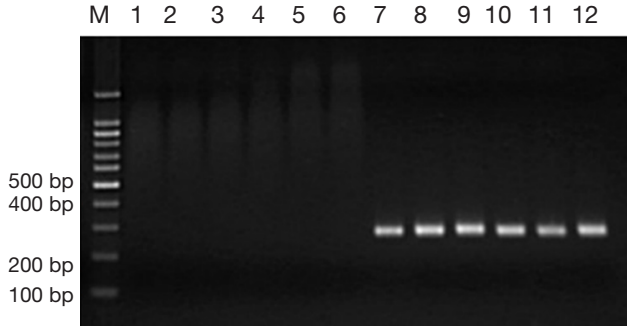

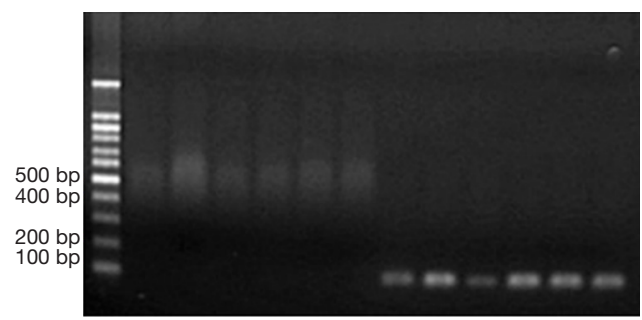

Figure 4 q-PCR analysis of pancreatic ductal epithelial cells. (A) GAPDH as the internal control; (B) CK-7; (C) CK-19; (D) somatostatin; (E) amylase; (F) insulin; (G) glucagon. Lanes 1-3: second passage of pancreatic ductal epithelial cells; lanes 4-6: fourth passage of pancreatic ductal epithelial cells; lanes 7-9: first pancreatic tissue harvested after main pancreatic duct removal; lanes 10-12: second pancreatic tissue harvested after main pancreatic duct removal.

epidermal growth factor (EGF), keratinocyte growth factor (KGF), cholera toxin, bovine pituitary extract, dexamethasone, soybean trypsin inhibitor, triiodo-Lthyronine, $0.5 \times$ insulin/transferrin/selenium complex (ITS), and fetal bovine serum $(10,19)$. In this study, RPMI-1640 was supplemented with $0.1 \%$ penicillin-streptomycin and $10-15 \%$ fetal bovine serum to prepare complete medium, which can maintain cell growth for 4-6 weeks, with 7-10 passages, consistent with the report by Trautmann et al. (7).

Previous reports considered fibroblast contamination to be a common problem in primary pancreatic ductal epithelial cell culture. There are two methods that address this issue: first, because fibroblasts are more likely to adhere than are ductal epithelial cells, the culture supernatant can be collected after $2 \mathrm{~h}$ and transferred to a new culture flask, therefore avoiding contamination (16); second, serumfree medium can be employed (10). In this study, the main pancreatic duct could be accurately located and separated. During the operation, the peripheral tissues of the main pancreatic duct could be carefully removed to avoid fibroblast contamination to the greatest extent possible. CK7 and CK19 are expressed by pancreatic ductal epithelial cells and somatostatin, amylase, insulin, and glucagon are not expressed $(7,20)$. In this study, Western blotting and 
q-PCR analyses confirmed that the second and fourth passages of cells were relatively pure in the pancreatic ductal epithelial cells of rats.

In previous reports, laminin (19), collagen, polylysine (21), and other Matrigel coating materials were applied to the bottom of the culture flask/dish to promote the growth of pancreatic ductal cells. This study, however, did not use the above substances, but the cells still adhered and grew, which indicates that the aforementioned extracellular matrix substances are not necessary for the in vitro culture of primary rat pancreatic ductal epithelial cells. This finding is consistent with the results of Furukawa et al. (22).

However, this study provides preliminary results and is not without certain limitations. For example, due to the small number of primary cells, Western blot and q-PCR analyses were not performed on primary cells; however, this limitation is expected to be addressed in future studies.

\section{Conclusions}

In summary, this study employed retrograde injection of $0.2 \%$ indigo carmine mucosa staining solution to determine the location of the main pancreatic duct in rats, and removed the main pancreatic duct using the naked eye. The pancreatic duct was sequentially digested with collagenase, neutral protease, and trypsin to obtain primary pancreatic ductal epithelial cells from the rats. The second and fourth passages of cells were verified to be relatively pure pancreatic ductal epithelial cells by Western blot and $\mathrm{q}-\mathrm{PCR}$ analyses. This method is simple in operation and is of certain practical value. For example, it does not require a stereomicroscope, which can shorten the operation time and avoid fibroblast pollution.

\section{Acknowledgments}

Funding: This work was supported by the National Natural Science Foundation of China (Grant No. 81260087 \& 81560111) and the Guangxi Natural Science Foundation (Grant No. 2017GXNSFAA198068).

\section{Footnote}

Conflicts of Interest: The authors have no conflicts of interest to declare.

Ethical Statement: The authors are accountable for all aspects of the work in ensuring that questions related to the accuracy or integrity of any part of the work are appropriately investigated and resolved. This study was approved by the Ethics Committee of the First Affiliated Hospital of Guangxi Medical University (Nanning, China) (No. 201702032). All procedures in the animal studies were performed in accordance with the ethical standards of the institution or practice.

Open Access Statement: This is an Open Access article distributed in accordance with the Creative Commons Attribution-NonCommercial-NoDerivs 4.0 International License (CC BY-NC-ND 4.0), which permits the noncommercial replication and distribution of the article with the strict proviso that no changes or edits are made and the original work is properly cited (including links to both the formal publication through the relevant DOI and the license). See: https://creativecommons.org/licenses/by-nc-nd/4.0/.

\section{References}

1. Grapin-Botton A. Ductal cells of the pancreas. Int J Biochem Cell Biol 2005;37:504-10.

2. Zhou Q, Melton DA. Pancreas regeneration. Nature 2018;557:351-8.

3. Sambathkumar R, Migliorini A, Nostro MC. Pluripotent Stem Cell-Derived Pancreatic Progenitors and betaLike Cells for Type 1 Diabetes Treatment. Physiology (Bethesda) 2018;33:394-402.

4. Tritschler S, Theis FJ, Lickert H, et al. Systematic singlecell analysis provides new insights into heterogeneity and plasticity of the pancreas. Mol Metab 2017;6:974-90.

5. Sakata N, Yoshimatsu G, Kodama S. Development and Characteristics of Pancreatic Epsilon Cells. Int J Mol Sci 2019.doi: 10.3390/ijms20081867.

6. Yuan S, Metrakos P, Duguid WP, et al. Isolation and culture of intralobular ducts from the hamster pancreas. In Vitro Cell Dev Biol Anim 1995;31:77-80.

7. Trautmann B, Schlitt HJ, Hahn EG, et al. Isolation, culture, and characterization of human pancreatic duct cells. Pancreas 1993;8:248-54.

8. Huang L, Holtzinger A, Jagan I, et al. Ductal pancreatic cancer modeling and drug screening using human pluripotent stem cell- and patient-derived tumor organoids. Nat Med 2015;21:1364-71.

9. Gmyr V, Kerr-Conte J, Vandewalle B, et al. Human pancreatic ductal cells: large-scale isolation and expansion. Cell Transplant 2001;10:109-21.

10. Hubchak S, Mangino MM, Reddy MK, et al. 
Characterization of differentiated Syrian golden hamster pancreatic duct cells maintained in extended monolayer culture. In Vitro Cell Dev Biol 1990;26:889-97.

11. Hootman SR, Logsdon CD. Isolation and monolayer culture of guinea pig pancreatic duct epithelial cells. In Vitro Cell Dev Biol 1988;24:566-74.

12. Githens S, Patke CL, Schexnayder JA. Isolation and culture of rhesus monkey pancreatic ductules and ductulelike epithelium. Pancreas 1994;9:20-31.

13. Sato T, Sato M, Hudson EA, et al. Characterization of bovine pancreatic ductal cells isolated by a perfusiondigestion technique. In Vitro 1983;19:651-60.

14. Reichert M, Rhim AD, Rustgi AK. Culturing primary mouse pancreatic ductal cells. Cold Spring Harb Protoc 2015;2015:558-61.

15. Reichert M, Takano S, Heeg S, et al. Isolation, culture and genetic manipulation of mouse pancreatic ductal cells. Nat Protoc 2013;8:1354-65.

16. Tsao MS, Duguid WP. Establishment of propagable epithelial cell lines from normal adult rat pancreas. Exp Cell Res 1987;168:365-75.

17. Zhang N, Gao D, Liu Y, et al. Effects of Neuropeptide

Cite this article as: Chang R, Qin H, Liang Z, Qin M, Wang H, Wei Y, Fu H, Huang H, Tang G. An improved method for the isolation and culture of rat pancreatic ductal epithelial cells. Ann Transl Med 2020;8(6):320. doi: 10.21037/atm.2020.03.75
Substance P on Proliferation and beta-Cell Differentiation of Adult Pancreatic Ductal Cells. Front Neurosci 2018;12:806.

18. Liu Y, Li Y, Chen KL, et al. Knockdown of Myeloid Differentiation Factor 88 Attenuates LipopolysaccharideInduced Inflammatory Response in Pancreatic Ductal Cells. Pancreas 2016;45:755-60.

19. Agbunag C, Lee KE, Buontempo S, et al. Pancreatic duct epithelial cell isolation and cultivation in two-dimensional and three-dimensional culture systems. Methods Enzymol 2006;407:703-10.

20. Lawson T, Ouellette M, Kolar C, et al. Culture and immortalization of pancreatic ductal epithelial cells. Methods Mol Med 2005;103:113-22.

21. Githens S. Pancreatic duct cell cultures. Annu Rev Physiol 1994;56:419-43.

22. Furukawa T, Duguid WP, Rosenberg L, et al. Longterm culture and immortalization of epithelial cells from normal adult human pancreatic ducts transfected by the E6E7 gene of human papilloma virus 16. Am J Pathol 1996;148:1763-70. 